\title{
Familial treacher collins syndrome- from an obstetrician's view
}

\section{Chesta Saini $^{1 *}$, Kishore Rajurkar ${ }^{1}$, Rizul Saini ${ }^{2}$}

${ }^{1}$ Department of Obstetrics and Gynaecology, ${ }^{2}$ Department of Anaesthesia, Sanjay Gandhi Memorial Hospital, Delhi, India

Received: 16 November 2020

Revised: 08 February 2021

Accepted: 09 February 2021

\section{*Correspondence:}

Dr. Chesta Saini,

E-mail: chesta.saini14@gmail.com

Copyright: (C) the author(s), publisher and licensee Medip Academy. This is an open-access article distributed under the terms of the Creative Commons Attribution Non-Commercial License, which permits unrestricted non-commercial use, distribution, and reproduction in any medium, provided the original work is properly cited.

\section{ABSTRACT}

A number of genetic syndromes have been identified and can be diagnosed antenatally using ultrasonography signifying the importance of antenatal care. We report a rare case of familial treacher collins syndrome diagnosed postnatally that shows difficulties faced by an obstetrician to safely manage such cases.

Keywords: Treacher collins syndrome, Unicornuate uterus, Craniofacial dysmorphism

\section{INTRODUCTION}

Treacher collins syndrome is a rare genetic syndrome that affects craniofacial morphogenesis. Around $40 \%$ of cases are familial and can be suspected and diagnosed prenatally by sonographic findings consisting of typical facial abnormalities along with polyhydramnios. ${ }^{1}$

\section{CASE REPORT}

An unbooked primigravida, aged 21 years with unsure dates, belonging to low socio-economic status, presented to our OPD for antenatal checkup at 9 months of amenorrhoea. She was admitted for Hypertension $(148 / 102 \mathrm{~mm} \mathrm{Hg})$. Her 1 st and 2nd trimesters were historically uneventful.

She had a single sonogram done in early 3rd trimester which showed polyhydramnios. On Examination, she was short statured $(121 \mathrm{~cm})$, with microtia on right side, maloccluded teeth, facial dysmorphism, laterally slanting eyes and left sided scoliosis. Per Abdomen, a single live intrauterine fetus was noted in longitudinal lie, cephalic presentation and unengaged head with normal fetal heart rate.

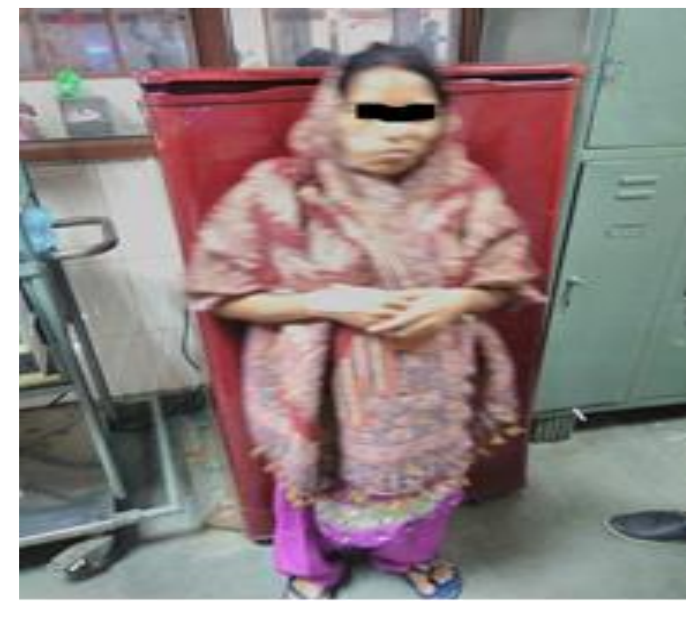

Figure 1: Short stature of patient.

Examination of other systems was unremarkable. Pelvic assessment was done and it revealed contracted pelvis. A diagnosis of TCS was made on the basis of clinical and radiological examination. Pre anaesthetic checkup was done and she was taken up for elective caesarean section at 39 weeks of gestational age after controlling BP and a male baby weighing $1.8 \mathrm{~kg}$ was delivered. 
Intraoperatively, the patient was found to have unicornuate uterus with absent fallopian tube on left side.

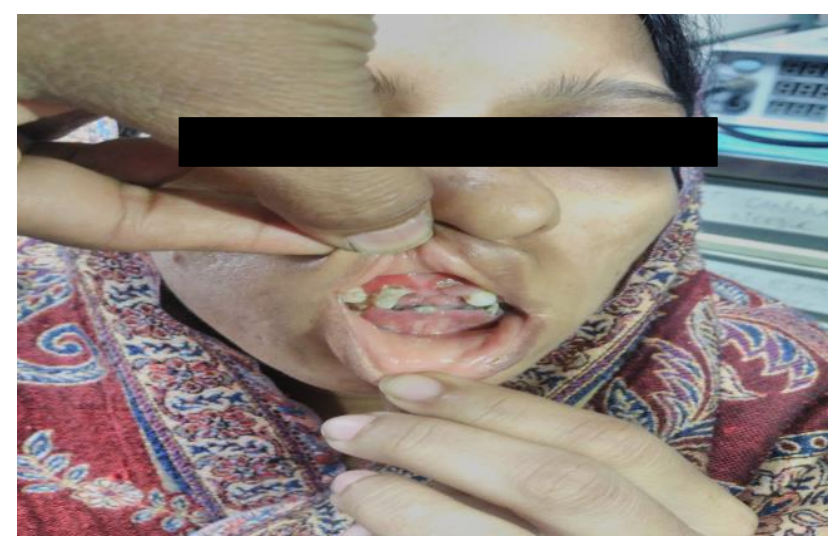

Figure 2: Maloccluded teeth, laterally slanting eyes.

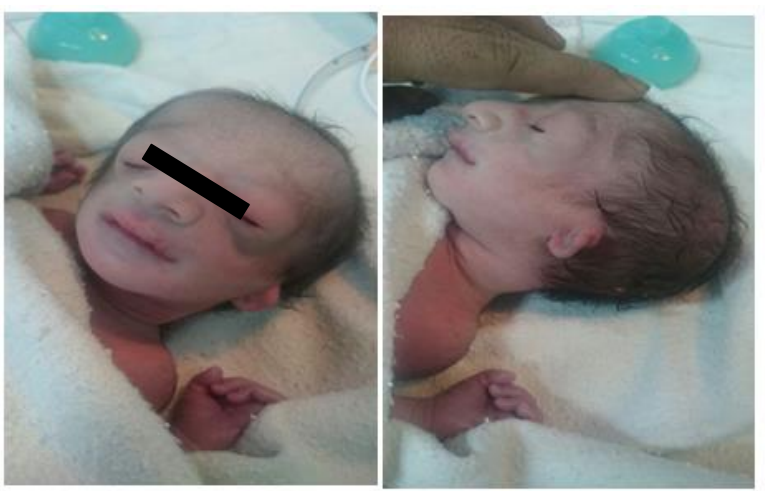

Figure 3: New-born with craniofacial dysmorphism, b/l microtia, cleft palate and micrognathia.

The infant revealed dysmorphic facial features, $\mathrm{B} / \mathrm{L}$ microtia, slanting palpebral fissures, cleft palate and micrognathia. Hypoplasia of mandibular bones was confirmed on skull X-ray and a diagnosis of Treacher Collin Syndrome made. Paternal findings also concluded in favour of TCS. The family was advised to undergo genetic testing but refused due to financial constraints.

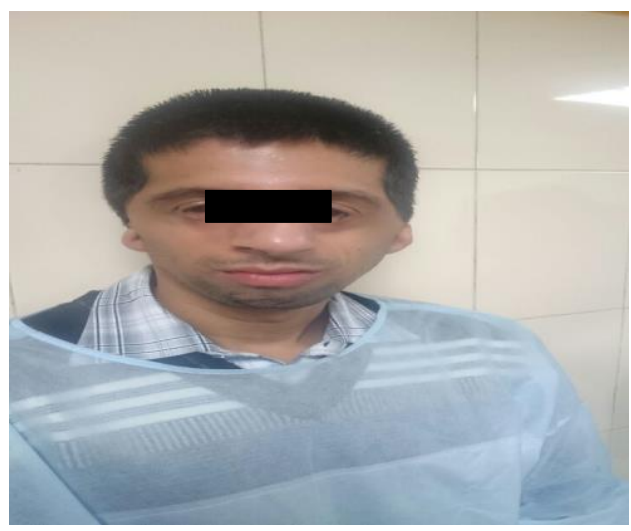

Figure 4: Father with craniofacial dysmorphism, b/l microtia and micrognathia.

\section{DISCUSSION}

Treacher collins syndrome (TCS, OMIM number 154500) or mandibulofacial dysostosis or FranceschettiZwahlen-Klein syndrome is an autosomal dominant disorder having growth diminution of craniofacial structures derived from the first and second pharyngeal arch, groove, and pouch. Its estimated incidence is $1 / 50000$ live births with more than $60 \%$ of the cases arising as de novo mutations.,

The mutations have been mapped to chromosome 5q3233.2 locus with insertions or deletions seen in the TCOF1, POLR1C, and POLR1D genes. These genes code for polymerase subunit components and a serine/alanine rich nucleolar phosphoprotein named "Treacle." Before the identification of the TCOF1 gene, diagnosis of TCS was possible only by linked polymorphic markers and clinical evaluation. The gene penetrance of TCS seems to be high, but the manifestations varies from mild to severe life threatening malformations. Thus when arriving at a diagnosis, the entire facial appearance needs to be considered, since there is a high degree of both inter- and intra-familial variability. 5,6

Prenatally it can be suspected based on 2D ultrasonographic findings in the second trimester (between the 18th and 20th week). Some of the subtle findings of facial dysmorphism can be more clearly illustrated by 3D ultrasonography, such as downslanting palpebral fissures or macrostomia. Moreover, secondtrimester also offers the possibility of invasive testing and the option for termination of pregnancy if desired.

Apart from the craniofacial dysmorphism, additional findings like encephalocele, ocular malformations, extracraniofacial anomalies involving thyroid, thymus, heart, splenules, ectopic adrenal gland tissue, and hypoplastic external genitalia have been more rarely described in the literature8. However, we couldn't find any study encountering contracted pelvis, unicornuate uterus or spine deformities as was seen in our case. Problems seen during caesarean section of a TCS patient while giving regional anaesthesia due to scoliosis as well as difficult extraction of free floating fetal head were few issues we had to deal with, besides the extensive care needed for growth restricted newborn with TCS. This case revealed the appalled state of antenatal care still reeling in our country and the need to identify such cases prenatally.

Genetic counseling should be made available for parents affected with the syndrome or for parents with a previous child showing features of TCS. It should be explained to the parents that the probability of their affected second child having same phenotypic features is negligible. ${ }^{4}$

In couples willing to continue such pregnancies, postnatal management requires multidisciplinary care (obstetrician, 
neonatologist, oromaxillofacial surgeon, otorhinologist and anesthesiologist). Delivery should be planned in specialized perinatal centres, since the new born may even require a tracheostomy for acute respiratory distress at birth.

Our ultimate goal should be to identify a chemical compound which if administered as prophylaxis during pregnancy can protect the embryo from apoptosis without any detrimental effects to the embryo during embryogenesis ( 3 to 12 week) when it is most susceptible to the development of craniofacial and other anomalies. Few animal studies have shown that genetic suppression of p53 causes suppression of apoptosis that leads to TCS. This could be an area of research to prevent the appearance of the syndrome in an offspring of parents affected by the same. However, this carries with it a risk of tumorigenesis since p53 is an important tumor suppressor. $^{7}$

Future research can target the use of stem cell therapy in the facial reconstruction of affected individuals. Till then early identification and tertiary care remains the mainstay of treatment.

\section{CONCLUSION}

Although sufficient data is available describing craniofacial abnormalities, not much published literature is available describing pelvic organ abnormalities and the technical difficulties faced by obstetricians and anaesthetists while managing such cases. This study would help us be better prepared in future to manage such cases from an obstetrician's point of view.

Funding: No funding sources

Conflict of interest: None declared

Ethical approval: Not required

\section{REFERENCES}

1. Edwards SJ, Fowlie A, Cust MP, Liu DTY, Young ID, Dixon MJ. Prenatal diagnosis in Treacher Collins. Otolaryngol Head Neck Surg. 1995;121:509-14.

2. Fazen LE, Elmore J, Nadler HL: Mandibulo-facial dysostosis (Treacher-Collins syndrome). Am J Dis Child 1967;113: 405-10.

3. Rovin S, Dachi SF, Borenstein DB, Cotter WB: Mandibulofacial dysostosis, a familial study of five generations. J Pediatr 1964;65:215-21.

4. Kasat V, Baldawa R. Treacher Collins syndrome - A case report and review of literature. J Clin Exp Dent 2011;3:e395-9

5. Dixon MJ, Marres HA, Edwards SJ, Dixon J, Cremers CW: Treacher Collins syndrome: correlation between clinical and genetic linkage studies. Clin Dysmorphol 1994;3:96-103.

6. Marres HA, Cremers CW, Dixon MJ, Huygen PL, Joosten FB: The Treacher Collins syndrome. A clinical, radiological, and genetic linkage study on two pedigrees. Arch Otolaryngol Head Neck Surg 1995;121: 509-14.

7. Li C, Mernagh J, Bourgeois J. Novel craniofacial and extracraniofacial findings in a case of Treacher Collins syndrome with a pathogenic mutation and a missense variant in the TCOF1 gene. Clinic Dysmorphol. 2009;18(1):63-6.

Cite this article as: Saini C, Rajurkar K, Saini R. Familial treacher collins syndrome- from an obstetrician's view. Int J Reprod Contracept Obstet Gynecol 2021;10:1185-7. 